\title{
DESAIN ULANG KEMASAN PRODUK MAKANAN TRADISIONAL JENANG KHAS KABUPATEB KUDUS UNTUK MENINGKATKAN DAYA BELI MASYRAKAT
}

\author{
Ayyub Hamdanu Nurmana Mulyana Slamet ${ }^{1}$, Mars Caroline Wibowo ${ }^{2}$ \\ ${ }^{1}$ Desain Grafis - Universitas STEKOM, ayyub@stekom.ac.id \\ ${ }^{2}$ Desain Grafis - Universitas STEKOM, mars@gmail.com \\ J1. Majapahit 605, Semarang, telp/fax : 024-6717201-02
}

\section{ARTICLE INFO}

Article history:

Received 30 September 2021

Received in revised form 2 Oktober 2021

Accepted 10 November 2021

Available online 17 Desember 2021

\begin{abstract}
Packaging is one part of the product as a whole. Packaging must be able to attract the attention of consumers. Getting the attention of consumers is very important, because if a product does not get the attention of consumers (consumer attention), then consumers will not have a picture of the product (Hine, 1995). Packaging can give an initial picture of a product, both in terms of quality and value offered. "Jenang Kudus" is a type of traditional food originating from the city of Kudus. At first it was produced in a home industry since about a century ago. Initiated by mothers as a supporter of family income, and marketed directly to local consumers in traditional markets. Because the development of this business in the future is considered quite prospective for the Kudus community, the Kudus Regency Government makes the Jenang Kudus product as the mainstay product of the Kudus Regency.

Based on some of the explanations above, there are several weaknesses in the packaging design of $\mathrm{CV}$ jenang products. Sinar Aisyah Kudus which can cause delays in the marketing process of its products due to unattractive packaging designs. This causes a desire to increase the competitiveness of jenang sales with other companies through attractive and varied packaging designs. Due to some of these things, raises the desire of CV. Hj Siti Aisyah to redesign the product packaging according to the type of jenang product, type of taste, quantity of contents, without leaving the characteristics of the previous design.
\end{abstract}

Keywords: Design, packaging, jenang, Traditional Products

\section{Pendahuluan}

Jawa Tengah dengan jumlah penduduk sekitar 32 juta jiwa, menjadi pangsa pasar yang sangat potensial bagi produsen produk apapun. Supaya konsumen tertarik untuk membeli produk yang ditawarkan, produsen menerapkan strategi pemasaran dengan menggunakan media massa sebagai sarana komunikasinya. Komunikasi antara produsen dengan konsumennya melalui iklan dirasa kurang efektif lagi. Selain karena produsen lain juga melakukan hal yang sama, iklan produk dimedia massa hanya sekedar memberikan awarness tentang keberadaan produk kepada konsumen. Hal tersebut tidak mempengaruhi keputusan pembelian konsumen atas produk itu secara langsung. 


\section{p-ISSN : 1979-0414 e-ISSN : 2621-6256}

Kemasan (Packaging) merupakan salah satu bagian dari produk secara keseluruhan. Kemasan harus mampu menarik perhatian konsumen. Mendapatkan perhatian konsumen sangat penting, karena apabila sebuah produk tidak mendapat perhatian konsumen (consumer attention), maka konsumen tidak akan mempunyai gambaran mengenai produk tersebut [1]. Kemasan dapat memberi gambaran awal mengenai suatu produk, baik itu dari segi kualitas maupun nilai yang ditawarkan. Pertanyaan yang muncul kemudian adalah bagaimana seharusnya kemasan itu didesain sehingga bisa diasosiasikan dengan produk berkualitas tinggi menurut pandangan (persepsi) konsumen [2]

"Jenang Kudus" adalah jenis makanan tradisional yang berasal dari kota Kudus. Pada awalnya diproduksi secara home industry sejak kurang lebih satu abad yang lalu. Dirintis oleh ibu-ibu sebagai penopang penghasilan keluarga, dan dipasarkan secara langsung ke konsumen lokal di pasar-pasar tradisional. Oleh karena perkembangan usaha ini di kemudian hari dipandang cukup prospektif bagi masyarakat Kudus, maka Pemerintah Kabupaten Kudus menjadikan produk Jenang Kudus sebagai produk andalan Kabupaten Kudus.

Diperkirakan di Kabupaten Kudus saat ini terdapat 40 pengusaha jenang. $85 \%$ termasuk skala mikro dan kecil, $15 \%$ termasuk skala menengah dan besar. Dari data tersebut dapat disimpulkan bahwa situasi persaingan pasar produk jenang diramaikan oleh 3 sampai dengan 5 pengusaha yang berada pada posisi sebagai market leader dan yang lainnya menempati posisi sebagai follower/peramai pasar. Perusahaan Jenang "CV. Hj Siti Aisyah" yang memproduksi Jenang Kudus merek "CV. Hj Siti Aisyah" dalam situasi persaingan itu dapat dimasukkan dalam jajaran kategori market leader.

CV. Hj Siti Aisyah selama ini dalam memasarkan produknya masih menggunakan metode penjualan dengan memasarkan secara langsung produknya ke konsumen melalui sales marketing yang dimilikinya. Selain itu CV. Hj Siti Aisyah juga membuka pusat penjualan produknya jadi satu dengan pusat produksinya yang berada di Jalan Kartono No. 183 Kudus. Sama juga dengan produsen jenang lainnya, CV. Hj Siti Aisyah memasarkan pula produknya ke supermarket yang ada di sekitar wilayah Kudus dan sampai ke Surabaya.

Pada beberapa produknya, CV. Hj Siti Aisyah mengemasnya dengan menggunakan plastik dengan desain yang tidak variatif. Terdapat beberapa kelemahan dalam pengemasan produknya yaitu :

a) Varian jenis produk jenang CV. Hj Siti Aisyah yang banyak, menyebabkan perlunya kemasan produk yang variatif. Kemasan yang sama di tiap produknya menyebabkan lemahnya daya saing dengan produk sejenis dari perusahaan lain.

b) Perbedaan desain kemasan produknya hanya berdasarkan teks rasa untuk tiap jenis produk jenang yang berbeda. Hal ini menyebabkan konsumen kurang tertarik dengan produk jenang yang dikemas, terutama produk jenang yang beraneka macam.

c) Pencitraan suatu produk yang dikemas kurang, hal ini dikarenakan kemasan produk jenang CV. $\mathrm{Hj}$ Siti Aisyah hanya menggunakan bahan plastik.

Berdasarkan beberapa penjelasan di atas, maka terdapat beberapa kelemahan dalam desain kemasan produk jenang CV. Hj Siti Aisyah yang dapat mengakibatkan terhambatnya proses pemasaran produknya dikarenakan desain kemasan yang kurang menarik. Hal ini menyebabkan adanya keinginan untuk meningkatkan daya saing penjualan jenang dengan perusahaan lain melalui desain kemasan yang menarik dan variatif.

\section{TINJAUAN PUSTAKA}

\section{Konsep Design}

Menurut Danton Sihombing desain grafis mempekerjakan berbagai elemen seperti marka, simbol, uraian verbal yang divisualisasikan lewat tipografi dan gambar baik dengan teknik fotografi ataupun ilustrasi. Elemen-elemen tersebut diterapkan dalam dua fungsi, sebagai perangkat visual dan perangkat komunikasi.

Menurut Suyanto desain grafis didefinisikan sebagai aplikasi dari keterampilan seni dan komunikasi untuk kebutuhan bisnis dan industri. Aplikasi-aplikasi ini dapat meliputi periklanan dan penjualan produk, menciptakan identitas visual untuk institusi, produk dan perusahaan, dan lingkungan grafis, desain informasi dan secara visual menyempurnakan pesan dalam publikasi.

Menurut Michael Kroeger visual communication (komunikasi visual) adalah latihan teori dan konsepkonsep melalui terma-terma visual dengan menggunakan warna, bentuk, garis dan penjajaran,

\section{Prinsip-Prinsip Design}

a. Keseimbangan (Balance)

Keseimbangan adalah keadaan atau kesamaan antara kekuatan yang saling berhadapan dan DESAIN ULANG KEMASAN PRODUK MAKANAN TRADISIONAL JENANG KHAS KABUPATEB KUDUS UNTUK MENINGKATKAN DAYA BELI MASYRAKAT 
menimbulkan adanya kesan seimbang secara visual. Prinsip keseimbangan ada dua, yaitu:

1) Keseimbangan formal (simetris).

Keseimbangan formal memberikan kesan sempurna, resmi, kokoh, yakin dan bergengsi.

Keseimbangan formal juga menyinggung mengenai konsistensi dalam penggunaan berbagai elemen desain. Semisal wana logo. Dalam desain kartu nama desain dibuat dengan full color $(\mathrm{F} / \mathrm{C})$. Tetapi dengan pertimbangan agar desain lebih variatif dan tidak membosankan, maka pada media desain yang berbeda Anda membuat logo tersebut dengan warna duotone.

2) Keseimbangan informal (asimetris).

Bermanfaat menghasilkan kesan visual yang dinamis, bebas, lepas, pop, meninggalkan sikap kaku. Karya seni dan desain harus memiliki keseimbangan agar nyaman dipandang dan tidak membuat gelisah. Seperti halnya jika kita melihat pohon atau bangunan yang akan roboh, kita merasa tidak nyaman dan cenderung gelisah. Keseimbangan adalah keadaan yang dialami oleh suatu benda jika semua dayan yang bekerja saling meniadakan. Dalam bidang seni keseimbangan ini tidak dapat diukur tapi dapat dirasakan, yaitu suatu keadaan dimana semua bagian dalam sebuah karya tidak ada yang saling membebani.

b. Kesatuan (Unity)

Kesatuan adalah kohesi, konsistensi, ketunggalan atau keutuhan, yang merupakan isi pokok dari komposisi. Kesatuan merupakan salah satu prinsip dasar tata rupa yang sangat penting. Tidak adanya kesatuan dalam sebuah karya rupa akan membuat karya tersebut terlihat cerai-berai, kacaubalau yang mengakibatkan karya tersebut tidak nyaman dipandang. Prinsip ini sesungguhnya adalah prinsip hubungan. Jika salah satu atau beberapa unsur rupa mempunyai hubungan (warna, raut, arah), maka kesatuan telah tercapai.

c. Penekanan (Aksentuasi)

Penekanan dimaksudkan untuk menarik perhatian pembaca, sehingga ia mau melihat dan membaca bagian desain yang dimaksud. Kalau dalam konteks desain surat kabar ini bisa dilakukan dengan memberikan kotak raster atas sebuah berita. Hal ini akan mengesankan pentingnya berita itu untuk dibaca oleh pembaca. Atau juga membesarkan ukuran huruf pada judul berita, sehingga terlihat jauh berbeda dengan berita lainnya. Penekanan juga dilakukan melalui perulangan ukuran, serta kontras antara tekstur, nada warna, garis, ruang, bentuk atau motif.

\section{d. Irama (Repetisi)}

Irama adalah pengulangan gerak yang teratur dan terus menerus. Dalam bentuk-bentuk alam bisa kita ambil contoh pengulangan gerak pada ombak laut, barisan semut, gerak dedaunan, dan lainlain. Irama merupakan selisih antara dua wujud yang terletak pada ruang, serupa dengan interval waktu antara dua nada musik beruntun yang sama. Desain grafis mementingkan interval ruang atau kekosongan atau jarak antar obyek. Misalnya jarak antar kolom. Jarak antar teks dengan tepi kertas, jarak antar 10 foto di dalam satu halaman dan lain sebagainya. Prinsip irama sesungguhnya adalah hubungan pengulangan dari bentuk -bentuk unsur rupa.

\section{e. Dominasi (Domination)}

Dominasi merupakan salah satu prinsip dasar tatarupa yang harus ada dalam karya seni dan deisan. Dominasi berasal dari kata Dominance yang berarti keunggulan. Sifat unggul dan istimewa ini akan menjadikan suatu unsure sebagai penarik dan pusat perhatian. Dalam dunia desain, dominasi sering juga disebut Center of Interest, Focal Point dan Eye Catcher. Dominasi mempunyai beberapa tujuan yaitu utnuk menarik perhatian, menghilangkan kebosanan dan untuk memecah keberaturan.

\section{f. Proporsi (Proportion)}

Proporsi termasuk prinsip dasar tata rupa untuk memperoleh keserasian. Untuk memperoleh keserasian dalam sebuah karya diperlukan perbandingan -perbandingan yang tepat. Pada dasarnya proporsi adalah perbandingan matematis dalam sebuah bidang. Proporsi Agung (The Golden Mean) adalah proporsi yang paling populer dan dipakai hingga saat ini dalam karya seni rupa hingga karya arsitektur.

\section{METODE PENELITIAN}

Untuk mendapatkan data dan informasi yang baik serta akurat dalam penulisan proposal ini, maka dibutuhkan metode penelitian antara lain :

1. Metode penelitian menggunakan prototyping yaitu : 


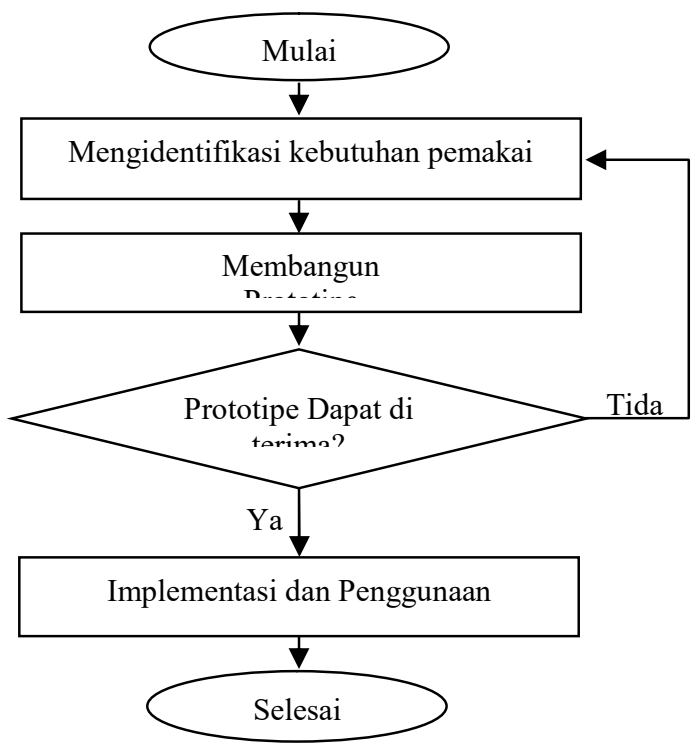

Gambar 1 Metode Prototyping

(Sumber : Abdul Kadir dan Terra Ch. Triwahyuni, 2005)

Keterangan langkah - langkah dalam prototyping:

a. Langkah pertama mengidentifikasi kebutuhan kemasan produk, mulai dari kebutuhan desain dan bahan yang akan digunakan dalam kemasan produk.

b. Berikutnya adalah membangun prototype. Prototype adalah alat yang digunakan untuk mensimulasikan desain kemasan sesuai dengan identifikasi kebutuhan dalam langkah pertama.

c. Selanjutnya adalah evaluasi dari prototype yang diajukan. Jika prototype dapat diterima maka selanjutnya kemasan produk dapat digunakan, tetapi jika prototype tidak diterima maka proses dimulai dari awal kembali.

d. Langkah yang terakhir adalah penggunaan kemasan produk.

2. Teknik Pengumpulan Data.

Untuk mendapatkan data-data yang relevan dan akurat yang dapat membantu penulis dalam mengumpulkan data, maka penulis menggunakan metode pengumpulan data sebagai berikut :

a. Wawancara.

Wawancara atau interview metode teknik pengumpulan data yang secara langsung, sehinga tidak melenceng dari objek. Dan dengan cara tanya jawab secara langsung dan sistematis dan berdasar pada tujuan penelitian. Tanya Jawab dapat dilakukan dengan konsumen maupun pimpinan perusahaan

b. Observasi.

Teknik pengumpulan data dengan cara melakukan pengamatan dan pencatatan secara sistematis pada objek penelitian. Untuk mengetahui lebih jelas tentang sifat dan kebenaran dari objek tersebut, misalnya dengan cara melihat atau mengamati secara langsung terhadap berbagai kegiatan promosi yang dilakukan .

c. Studi Pustaka.

Studi pustaka adalah data yang di peroleh secara tidak langsung dari subjek atau objek yang diteliti, melainkan melalui pihak lain, seperti: buku, observasi, data data pendukung dan lainlain yang berhubungan dengan penelitian ini.

\section{HASIL PENELITIAN DAN PEMBAHASAN}

Perancangan ulang kemasan produk jenang CV. Hj Siti Aisyah menggunakan dua software pengolah gambar yaitu Adobe Photoshop sebagai pengolah gambar untuk desain background yang berisikan gambar dan foto. Sedangkan teks dalam kemasan produk jenang Kudus CV. Hj Siti Aisyah menggunakan software CorelDraw. 
a. Membuat desain perwajahan bagian depan kemasan.

1) Menjalankan software Adobe Photoshop, setelah terbuka adobe Photoshop, menentukan lembar kerja baru.

2) Membuka layer baru, memilihgradient tool dalam tool box untuk menentukan warna gradasi background kemasan. Menentukan dua warna gradasi, set warna pertama dengan jingga (R:233, G:128, B:28) dan warna kedua dengan coklat (R:131 , G:29 , B:9 ). Drag arah melintang dari sudut kiri atas ke kanan bawah. Buka Adobe Photoshop CS2,

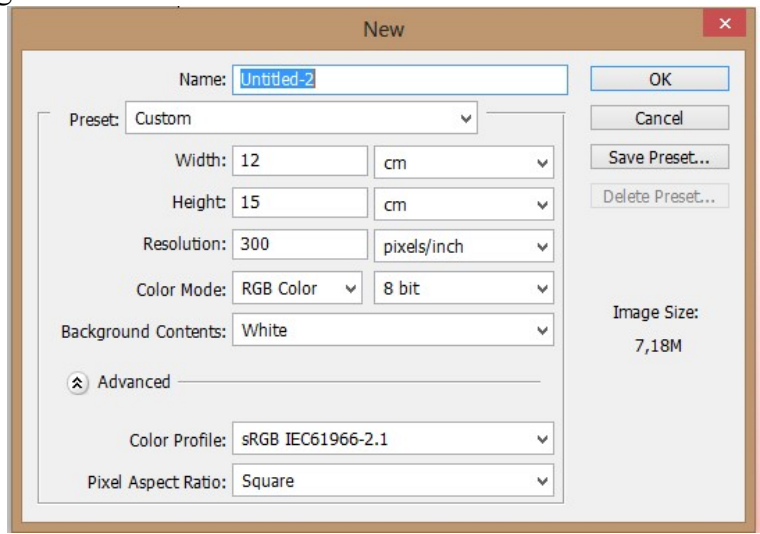

Gambar 2 tampilan ukuran awal

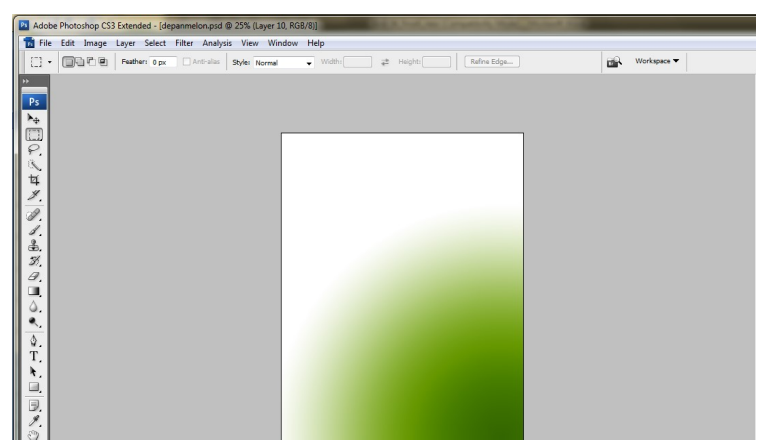

Gambar 3 Background Kemasan Jenang

3) kemudian buat file baru untuk mendesign melon dan strawberry dengan cara File- New kemudian buat ukurannya seperti di bawah ini

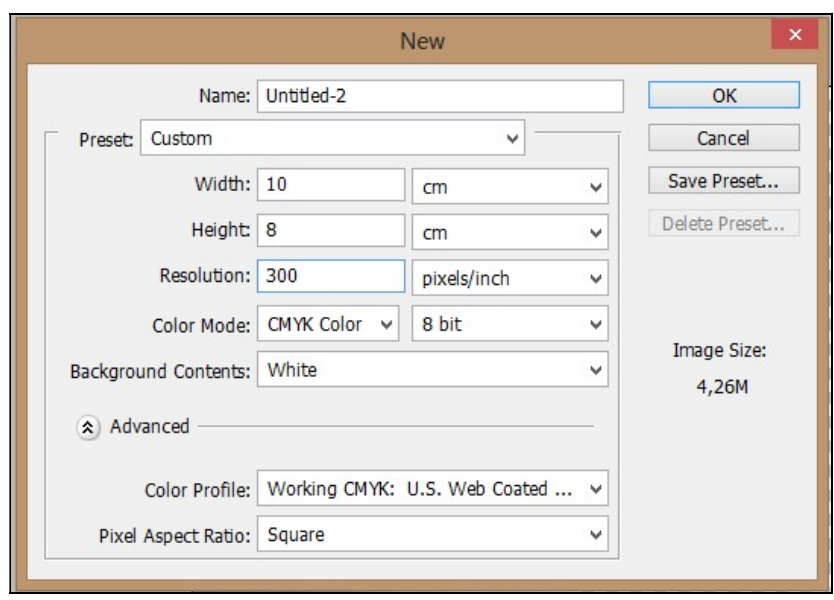

Gambar 4 ukuran susu melon 
p-ISSN : 1979-0414 e-ISSN : 2621-6256

4) Import gambar dengan cara file- place. Kemudian place gambar susu yang mengalir.

\begin{tabular}{|c|c|}
\hline \begin{tabular}{l|ll} 
File & Edit Image Layer
\end{tabular} & Select Filter View \\
\hline New... & $\mathrm{Cut}+\mathrm{N}$ \\
\hline Open... & $\mathrm{Ctrl}+\mathrm{O}$ \\
\hline Browse... & Alt + Ctrl +0 \\
\hline \multicolumn{2}{|l|}{ Open Recent } \\
\hline Edit in ImageReady & Shift $+C t r l+M$ \\
\hline Close & $\mathrm{Ctrl}+\mathrm{W}$ \\
\hline Close All & Alt $+C$ Ctrl+W \\
\hline Close and Go To Bridge... & Shift+Ctrl+W \\
\hline Save & $\mathrm{Ctul}+\mathrm{S}$ \\
\hline Save As... & Shift+Ctrl+S \\
\hline \multicolumn{2}{|l|}{ Save a Version... } \\
\hline Save for Web... & Alt + Shift $+C t r l+S$ \\
\hline Revert & $\mathrm{F} 12$ \\
\hline \multicolumn{2}{|l|}{ Place... } \\
\hline Import & • \\
\hline Export & • \\
\hline
\end{tabular}

Gambar 5 open file melon

5) File - palce lagi untuk mengimport gambar melon dan rasterize layer.

6) Pada gambar melon hapus bagian backgroundnya dengan cara memakai magic wand tool + shift agar yang diambil hanya bagian buahnya saja.

7) Jika sudah selesai, pilih select-feather dengan radius 2, tekan delete pada keyboard. Hingga hasil potongannya halus, tekan $c t r l+D$ untuk menghilangkan seleksi.

8) Pilih image-adjustment-levels untuk mengubah level warna pada buah agar semakin muncul warnanya.

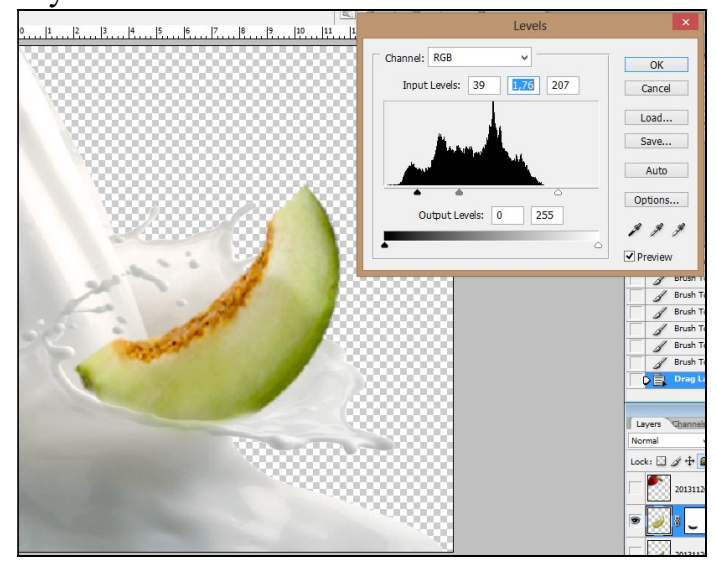

Gambar 6 Gambar susu dan melon diubah level

9) Non aktifkan simbol mata pada layer background, agar hasilnya transparan. Kemudian crop hingga hasilnya seperti di bawah ini.

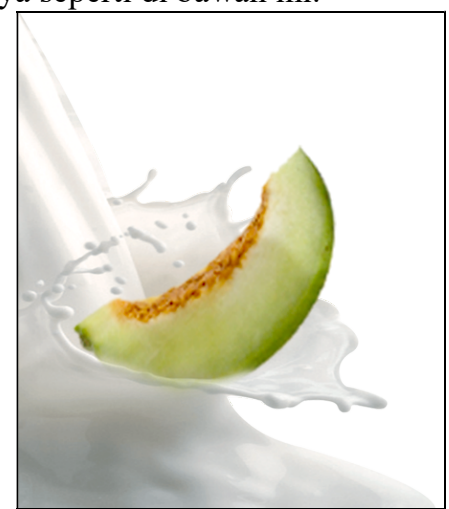

Gambar 7 hasil akhir perpaduan susu dan melon 
10) Simpan dengan cara save as-pilih type $P N G$ dengan nama melon.

11) Memberikan gambar melon dalam gambar background, dengan membuka gambar melon.jpg. Menghilangkan warna putih menggunakan magic wand tool dalam tool box, kemudian hapus area putih yang terseleksi. Drag gambar melon ke lembar kerja baru yang telah disiapkan sebelumnya. Menganti namalayer gambar melon menjadi melon.

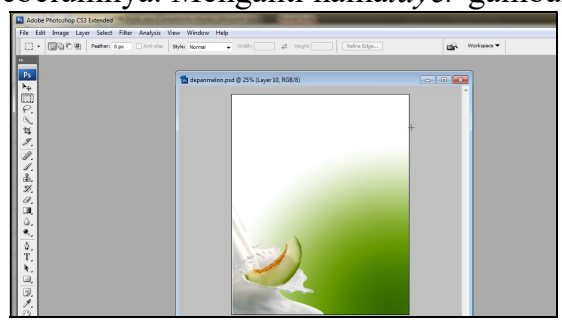

Gambar 8 Background Kemasan ditambah melon dan susu

12) Memasukkan gambar menara Kudus sebagai ciri kemasan produk jenang CV. Hj Siti Aisyah Kudus. Gambar menara Kudus mempunyai warna background yang bervariasi, untuk menyeleksi gambar menara Kudus digunakan pen tool agar penyeleksian bisa presisi.Drag gambar menara Kudus tanpa background ke lembar kerja baru yang telah disiapkan. Mengganti layer gambar menara Kudus menjadi manara.

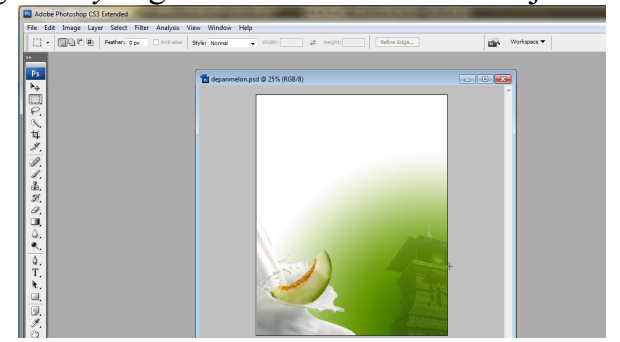

Gambar 9 Gambar setelah ditambah Melon dan Menara Kudus

13) Mengaktifkan lembar kerja baru yang telah dibuat menggunakan menu Window. Mengatur posisi gambar melon disebelah kiri kemasan dan gambar menara Kudus di sebelah kanan kemasan.

14) Menambahkan ornament pita warna merah dalam layer baru dengan warna kuning untuk menempatkan teks nama perusahaan dan alamat CV. Hj Siti Aisyah.

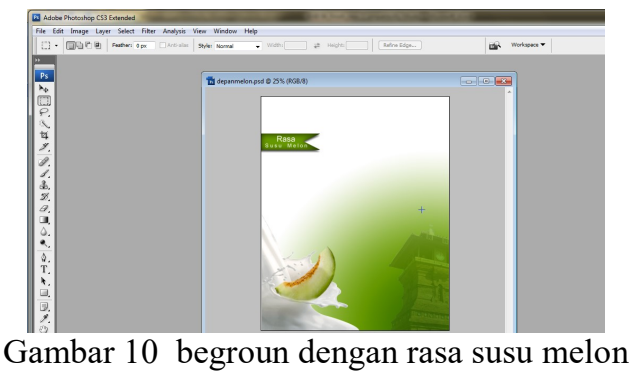

15) Setelah jadi ubah menjadi path menjadi seleksi menggunakan path panel. Klik kanan dalam dalam layer path, kemudian klik Make Selection. Tentukan Feather Radius menjadi 1 , klik OK.

16) Memberikan warna dalam area seleksi menggunakan menu Edit, klik Fill, tentukan nilai R:255, G:255, B:0. Klik Ok untuk menyetujui pengaturan warnanya.

17) Memperkecil area seleksi dengan menggunakan menu Select, pilih Modify, klik Contract. Tentukan nilai menjadi Contract by menjadi 15 pixel, kemudian klik OK.

18) Menghapus ornamen gambar sesuai area seleksi yang telah diatur sebelumnya. Membuat layer baru, klik menu Edit, klik Fill, atur warna dengan nilai R:57, G:142, B:0. 


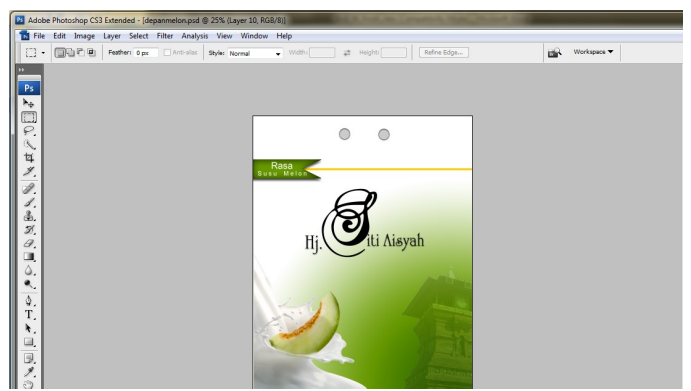

Gambar 11 Ornamen garis kuning setelah diberi warna

19) Mengatur bevel and emboss pada layer garis gambar warna kuning menggunakan layer style.

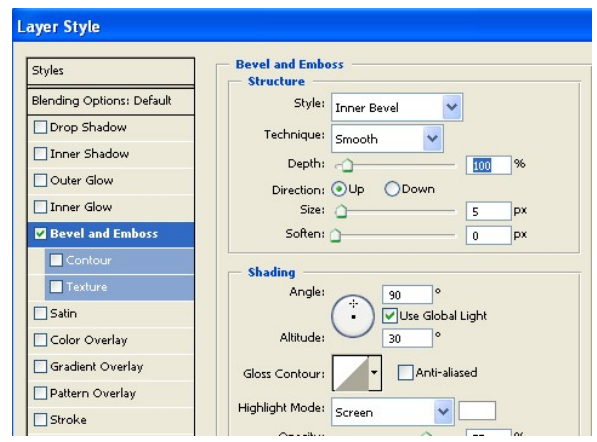

Gambar 12 Pengaturan Layer Style dalam garis warna kuning

20) Menambahkan teks $\mathrm{Hj}$. Siti Aisyah sebagai merek jenang Kudus produk CV. Hj Siti Aisyah menggunakan huruf ScriptMT Bold dengan ukuran 58 point dan Vivaldi dengan ukuran 53 point yang diletakkan rata tengah secara horizontal dekat tepi atas perwajahan kemasan bagian atas, dengan warna putih.

21) Menambahkan stroke dengan pengaturan warna R:86, G:86, B:86, memberikan kesan kokoh pada teks merek Hj. Siti Aisyah. Selain itu juga memberikan drop shadow, dan bevel and emboss.

22) Teks Rasa Susu Melon diberikan pengaturan layer style outer glow dan stroke untuk memberikan kesan lebar dan terang. Warna stroke diatur hijau dan warna stroke kuning muda.

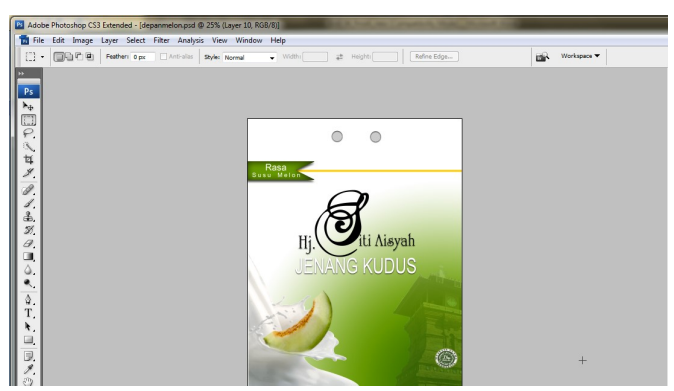

Gambar 13 Background Kemasan ditambah logo halal

23) Menambahkan teks Jenang Kudus dengan warna putih menggunakan jenis huruf MyriadPro Reguler, ukuran 25 point. Teks tersebut diletakkan di atas teks merek agak ke
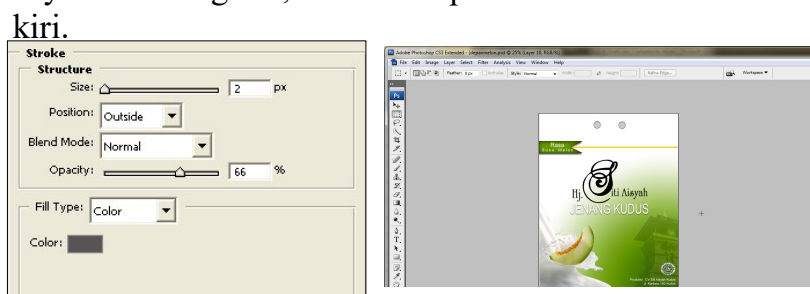

Gambar 14 Background Kemasan di tambah CV. Hj Siti Aisyah 
24) Menambahkan teks Juara Rasa dengan warna putih dan diletakkan dibawah teks merek agak ke kanan. Teks juara rasa menggunakan jenis huruf Chopin Script ukuran 34 point.

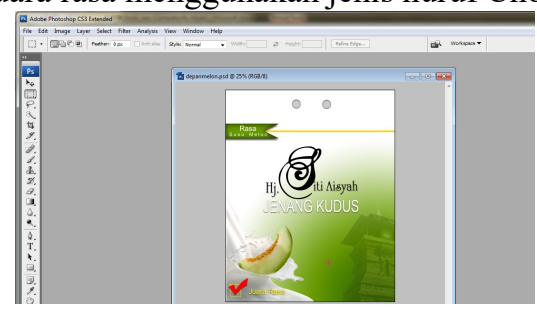

Gambar 15 Background Kemasan ditambah tulissan juara rasa

25) Menambahkan teks nama perusahaan CV. Hj Siti Aisyah dan alamat perusahaan yang diletakkan di bagian bawah kemasan agak ke kiri.

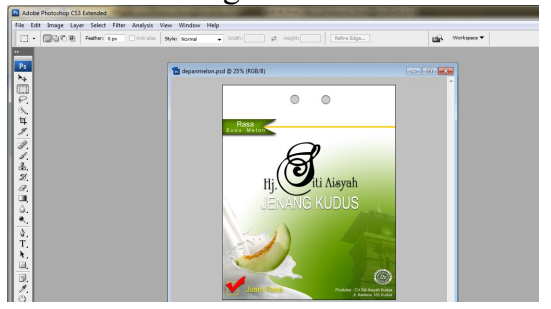

Gambar 16 Hasil Akhir Perwajahan bagian depan Kemasan

b. Membuat desain perwajahan bagain belakang kemasan

1) Pembuatan background menggunakan warna gradasi dan arah gradasi yang sama dengan desain perwajahan bagian depan kemasan.

2) Menambahkan gambar jenang kudus dan meletakkan dibagian kiri kemasan. Menambahkan masking untuk menutup sebagian gambar jenang memberikan gradasi warna hijau dan putih dengan arah melingkar pada masking yang telah tambahkan.

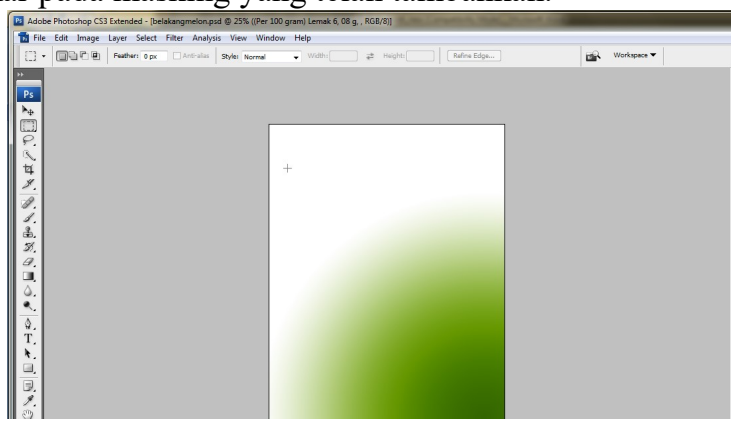

Gambar 17 Background Perwajahan Bagian Belakang Kemasan

3) Copy gambar ornament gelombang dari desain perwajahan bagian depan kemasan. Membalik gambar garis tersebut secara horizontal menggunakan menu Edit, Transform, klik Flip horizontal.

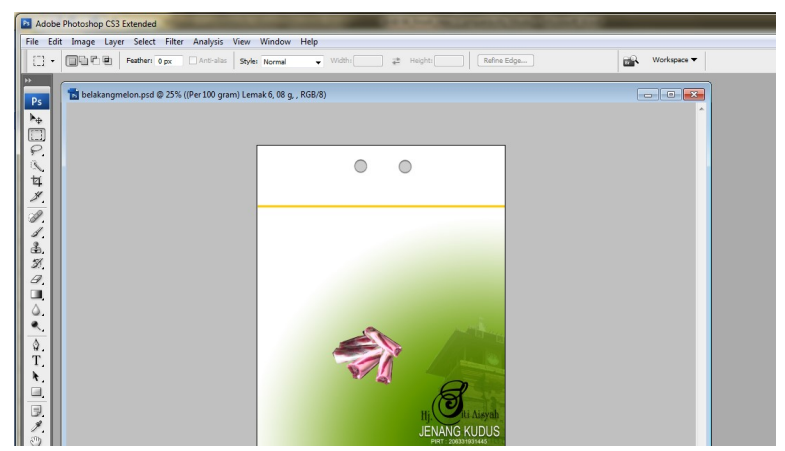

Gambar 18 Background Kemasan tambah gambar produk jenang

JURNAL ILMIAH KOMPUTER GRAFIS Vol. 14, No. 1, Desember 2021 : 16 - 27 
p-ISSN : $1979-0414$ e-ISSN : 2621-6256

4) Menambah gambar logo pada bagian kiri dan menambahkan teks nomor PIRT dan Exp. Date sebagai tangal batas kadaluarsa.

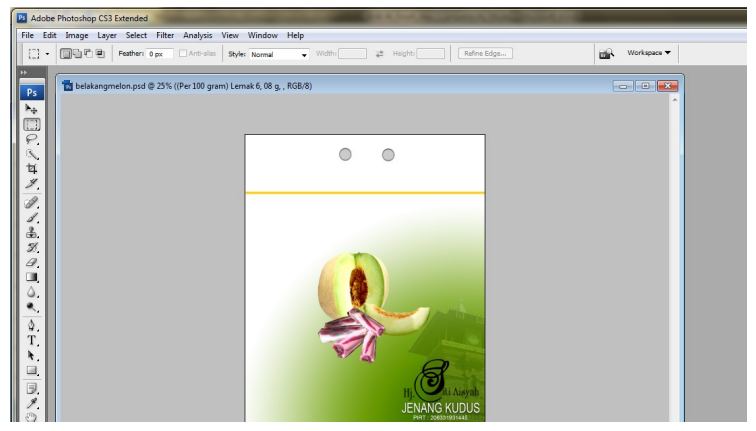

Gambar 19 Background Kemasan teks nomor PIRT dan Exp

5) Menambahkan komposisi yang terkandung dalam pembuatan jenang

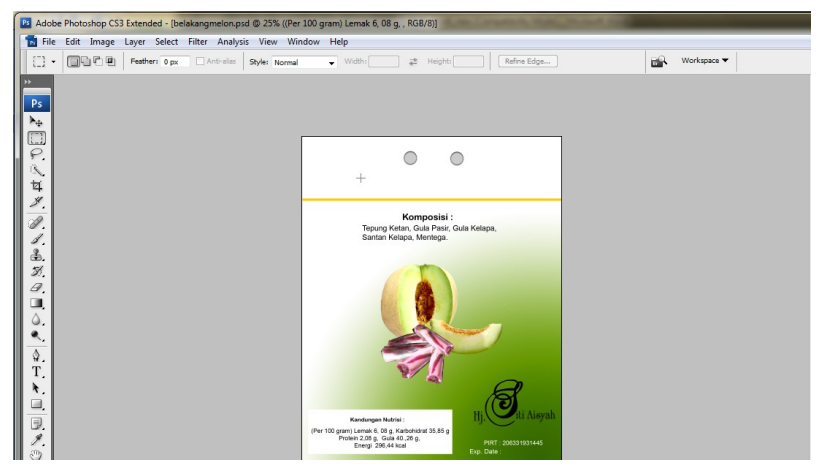

Gambar 20 Background Kemasan ditambah komposisi

6) Menambahkan kotak warna putih di samping teks Exp. Date agar dapat diisi dengan tanggal kadaluarsa produk oleh CV. Hj Siti Aisyah.

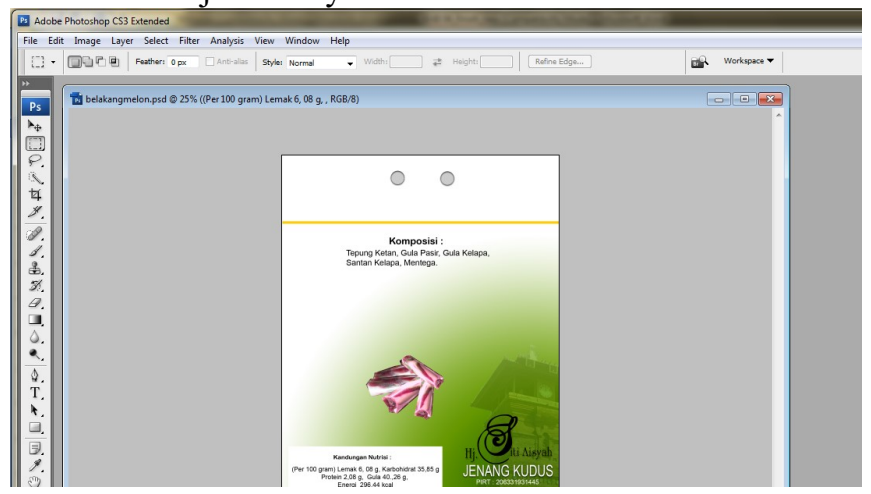

Gambar 21 Penambahan kotak warna putih di samping teks Exp. Date

7) Membuka Corel Draw untuk menyusun desain perwajahan kemasan sesuai dengan posisinya.

8) Buat prototype kemasan menggunakan rectangle tool, susun sesuai dengan ukuran yang telah ditentukan. 


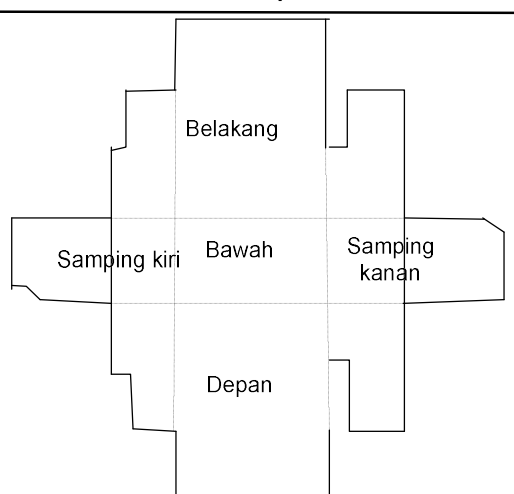

Gambar 22 Prototipe Kemasan Baru Produk Jenang Kudus CV. Hj Siti Aisyah

9) Menempatkan desain gambar perwajahan kemasan bagian depan dan belakang sesuai dengan posisinya.

10) Memutar desain perwajahan kemasan bagian belakang secara horizontal dan vertical menggunakan mirror tool dalam toolbar standar setelah memilih pict tool dalam tool box.

11) Memberikan warna pada bagian atas kemasan dengan waran orange (C:2, M:64, Y:96, B:0), memberikan warna bagian bawah kemasan dengan warna hijau (C:66, M:23, Y:100, K:11). Memberikan warna pada bagian samping kemasan dengan warna putih (C:25, M:86, Y:99, $\mathrm{K}: 33)$.

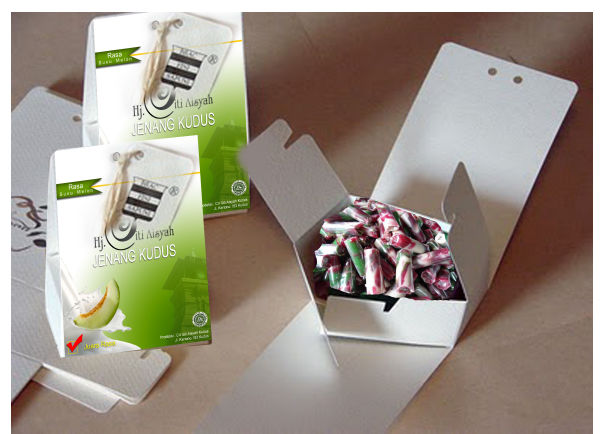

Gambar 23 Hasil Akhir Desain Kemasan Rasa Susu Melon

\section{KESIMPULAN DAN SARAN}

a. Kesimpulan

Pembahasan mengenai "Desain Ulang Kemasan Produk Makanan Tradisional Jenang Kudus pada CV. Hj Siti Aisyah"., dapat disimpulkan bahwa dengan adanya Desain ulang yang menarik, akan didapatkan berbagai macam keuntungan yang dapat dicapai antar lain :

1) Diharapkan dapat memberikan kesan yang berbeda pada produk jenang kudus, sehingga dapat menarik konsumen baru di luar pusat penjualan produk jenang CV. Hj Siti Aisyah..

2) Diharapkan hal ini dapat memberikan visualisasi bagi konsumen untuk produk jenang yang diproduksi oleh CV. Hj Siti Aisyah

3) Dengan adanya desain ulang ini diharapkan perusahaan mengalami peningkatan jumlah konsumen.

b. Saran

Berdasarkan hasil analisa dan pembahasan masalah dalam Skripsi ini, maka penulis memberikan saran yaitu : Desain kemasan yang akan di buat jangan hanya desain kemasan produk untuk rasa strowbery, dan melon dengan berat produk 600 gram perbungkus

JURNAL ILMIAH KOMPUTER GRAFIS Vol. 14, No. 1, Desember 2021 : $16-27$ 
p-ISSN : 1979-0414 e-ISSN : 2621-6256

\section{DAFTAR PUSTAKA}

Cahyadi, Dian, 2009; "Metodologi Desain”, http://blog.unm.ac.id/ diancahyadi/layanan-mk-2/layanan-mkmetdes/

Danger, Enc P., 1992; “Memilih Warna Kemasan”, Pustaka Binaman Pressindo, Jakarta.

Gobe, Marc, 2003; “Emotional Branding”, Penerbit Erlangga, Jakarta.

Hine, Thomas, 1995; “The Total Packaging”, Litle Brown Company, Boston.

Kadir, Abdul dan Terra Ch. Triwahyuni, 2005; "Pengenalan Teknologi Informasi", Yogyakarta: Andi Offset

Lofgren, Martin dan Lars Witell, 2005; “Kano's Theory of Attractive Quality and Packaging”, The Quality Managemen Jurnal, p:7.

Sihombing, Danton, 2001; "Tipografi Dalam Desain Grafis", Institut Seni Indonesia Yogyakarta [www.tipsdesain.com]

Sitepu, Vinsensius, 2006: “Panduan Mengenal Desain Grafis", Jakarta: Escaeva

Susanti, Ariana, 2002; “Aspek Legal dalam Desain”, Makalah dalam PraKonvensi Desain Nasional, Surabaya.

Widyatama, Rendra, 2005; “Pengantar Periklanan”, Buana Pustaka Jakarta.

Wirakusumah, Teddy, K, 2008; "Desain Komunikasi Visual untuk Social Marketing”, situs : http://teddykw.wordpress.com/2008/02/25/desain-komunikasi-visual-media-promosi-socialmarketing/ 